\title{
Gulf of Mexico ecosystem restoration: a risk-based integrated environmental, economic, and social resource management decision support framework
}

\author{
D. Hanson ${ }^{1}$, L. Hachmeister ${ }^{1}$, D. Hale ${ }^{2}$ \& E. Hassler ${ }^{2}$ \\ ${ }^{1}$ HansonRM, USA \\ ${ }^{2}$ Aging Infrastructure Systems Center of Excellence, \\ University of Alabama, USA
}

\begin{abstract}
The natural systems that make up the United States coastal waters of the Gulf of Mexico, its watershed, and adjacent marine waters serve as critical natural infrastructure supporting water supply, transportation, power generation, recreation, commercial fishing, agriculture, forestry, manufacturing, and a wide variety of other valued resources for the people in the watershed. Development activities, multiple uses, and both natural and human-induced disasters have placed significant stresses and impacts on the unique biodiversity of the ecosystem and its sustainable uses. This paper presents results of Phase 1 of a NOAA-funded assessment of the freshwater and marine fisheries that focused on the Mobile Bay (Alabama, USA) watershed, the related aquatic system, and the stresses placed on this system by both anthropologic and natural conditions. Three collaborative multi-stakeholder workshops were held in order to gain a perspective on the most immediate perceived threats to a sustainable Mobile Bay system. Challenges associated with the governance of the Mobile Bay system were ranked as the greatest category of threat for a sustainable system compared to more traditional anthropologic-perturbations such as habitat loss, non-point source pollution, or aging infrastructure. A decision support system framework was developed to better understand and quantify interactions between environmental, economic, social, and built capital systems. Following the Deepwater Horizon oil release in 2010, the system framework was modified to align with the five long-term ecosystem restoration goals and priority actions
\end{abstract}


identified in the President's Task Force for a regional Gulf of Mexico ecosystem restoration strategy.

Keywords: Gulf of Mexico ecosystem restoration decision support system, DSS, coastal resilience, habitat restoration, water quality, Mobile Bay watershed.

\section{Introduction}

The economies of the five U.S. Gulf of Mexico (GoM) coastal states (e.g., Texas, Louisiana, Mississippi, Alabama, and Florida) are heavily influenced by their marine and seafood industries, which include such broad elements as transportation, international trade, manufacturing, recreational and commercial fisheries, defence, oil and gas, recreation and tourism. The sustainability and viability of these industries are highly dependent and interdependent on the condition of their individual infrastructure systems and the interaction of these systems with the physical and biological environments.

Members of the Gulf Coast community and its upstream watersheds make decisions on a daily basis that impact the natural resources of the region and the economic and social well-being of the communities served. These decisions are complex in nature and often must address multiple goals with varying criteria and restrictions. Unfortunately, the health and restoration of Gulf Coast infrastructure systems are too often assessed in isolation from the inter-connected environmental, social, economic, and related human-built infrastructure systems. It is imperative that ecosystem and socioeconomic interactions be understood holistically in order to effectively conserve, protect, and enhance their health.

The seafood industry is a valued part of the region's culture and produces approximately $90 \%$ of the U.S. oyster and $82 \%$ of its shrimp production $[1,2]$. In the past decade, seafood industry revenue has declined due to losses from hurricanes (e.g. Katrina, Ivan, Dennis, and Rita), rising fuel prices, declining water quality and habitat, and declining import-related dockside prices. More recently, both direct and indirect impacts to the fisheries have resulted from the Deepwater Horizon oil spill. Collectively, these events have resulted in job losses, idle processing plants, and distressed communities [3]. In 2007, in response to concerns of the long-term sustainability of coastal seafood industry and associated GoM fisheries, Congress requested a fisheries infrastructure pilot study focused on the Mobile Bay watershed and nearby coastal waters off Alabama. The initial objective of the study, as summarized by U.S. Senator Richard Shelby [4], was: "The Fisheries Infrastructure Investigation, Assessment and Improvement Project was initiated to develop critical systems for private and public sectors to use in the evaluation of infrastructure needs along the Gulf Coast. The project examines fisheries' infrastructure considering all of the uses and impacts rather than only evaluating on a narrow set of criteria. The intent is to provide policy makers, industry and the public at large with a complete picture of the needs of the industry and the impacts on and by the needed infrastructure." 
Implementation of this study was significantly impacted following the Deepwater Horizon Oil Spill. On April 20, 2010 the Deepwater Horizon oil platform exploded and sank approximately 98 miles south of the Alabama coast releasing millions of barrels of crude oil into the GoM in the largest oil spill in U.S. history. In response to the economic and environmental impacts associated with the Deepwater Horizon incident and at the request of President Barack Obama, the Mabus report [5] explicitly recognized and addressed the importance of the linkages among economic, social, and environmental systems. Following extensive public review and input and based on recommendations from the Mabus Report, the Gulf Coast Ecosystem Restoration Task Force (GCERTF) identified historical and ongoing major stressors on the Gulf system (beyond those associated with only the Deepwater Horizon incident) and prepared a longterm strategy for restoration of the GoM ecosystem [6]. The restoration strategy included four major goals and corresponding priority actions to address the most prominent issues affecting the Gulf ecosystem, and recommended that implementation of the restoration strategy be supported by development of a decision support system framework with associated decision systems and tools.

Senior members of the Task Force recognized the similarities between the issues identified in the restoration strategy with those incorporated into our draft report and requested that we modify our efforts to:

1. align our findings and recommendations with the Task Force's long-term ecosystem restoration strategy

2. develop our recommendations such that Mobile Bay might be a pilot study for a decision support framework that could be applied across the entire Gulf Coast

This paper summarizes the results of Phase 1 of our NOAA-funded study, which prepared a decision support system framework aligned with the long-term ecosystem restoration for the U.S. waters of the GoM, including interactions with socieoeconomic systems in the watershed. As discussed in Section 5, detailed preparation and implementation of a decision support system is best done in a collaborative manner under funding from the Restore Act.

\subsection{Study area.}

The initial study area for this investigation was Mobile Bay, its watershed, and the nearby waters of the Gulf extending out to a depth of 100 fathoms (Fig. 1). We refer to this study area and its resources as the Mobile Bay Fisheries System (MBFS). Mobile Bay drains the fourth largest watershed in the United States in terms of flow volume due to the high annual precipitation in the region. The Mobile-Tensaw River Delta is the largest intact delta in the United States and covers approximately 289 square miles of marsh, swamp, and forested wetlands $[7,8]$. The Mobile Bay basin is characterized by barrier islands, tidal marshes, cypress swamps, bottomland hardwoods, and oyster reefs.

The Mobile Bay watershed and nearby Alabama aquatic systems have the highest diversity of freshwater species in the U.S., including more than 750 species of freshwater fish, mussels, snails, and crayfishes [9]. Unfortunately, no state east of the Colorado River has more wildlife species at risk, and only 
Hawaii has lost more species to extinction. Alteration of the natural landscape and waterways has contributed to the extinction or extirpation of more than 100 animal species $[9,10]$.

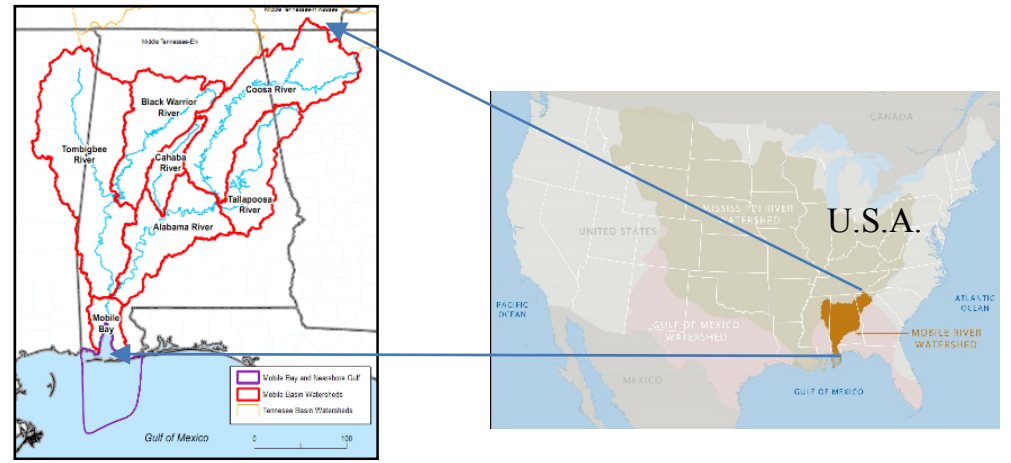

Figure 1: Location of Mobile Bay watershed and offshore waters (left panel and the focus of this pilot study), and the entire watershed and offshore waters of the GoM (right panel).

\subsection{Project approach}

The MBFS investigation was developed assuming a phased approach, with the initial focus on: defining the baseline systems and their conditions; identifying relevant decision support system (DSS) components and their qualitative interactions through stakeholder engagement; and developing a conceptual framework for the MBFS-DSS Framework (Fig. 2). Subsequently, this

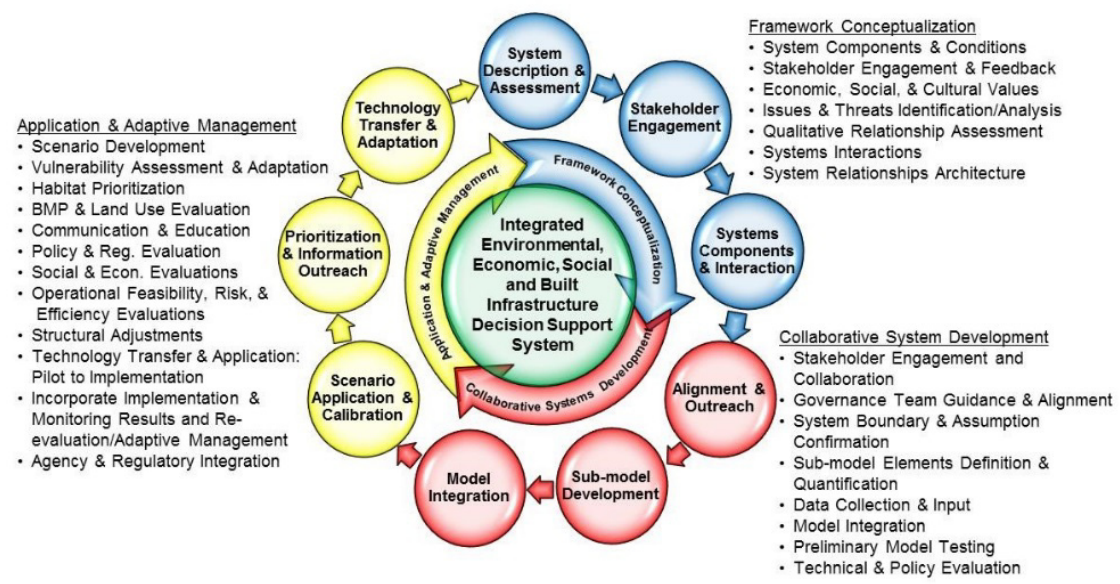

Figure 2: Three phase approach to the project. This paper represents the results from the framework conceptualization phase. 
investigation has defined a three-phase program to develop and implement this conceptual framework, the first of which is addressed in this paper.

\section{Stakeholder workshops: issues and priorities}

After preparing a preliminary summary of the environmental, social, economic, and built infrastructure capitals related to the MBFS, an academic-industrygovernment workshop was held at The University of Alabama to begin defining details of a MBFS-DSS Framework suitable for making multi-criteria, multistakeholder decisions that would incorporate multiple perspectives within a highly variable set of boundary conditions. Building on this initial workshop and other related studies [2, 3, 7-9, 11], additional stakeholder workshops were held in 2009 along the coastal estuary (Mobile, AL) and in the watershed (Montgomery, Al). These workshops engaged a broad array of public, government, NGO, and industrial stakeholders representing varying interests to identify the uses, limitations, and challenges for the Mobile Bay system, and to identify the factors that pose the greatest threat to those uses and a sustainable system.

When analysed for macro-level themes, five primary categories of interests and threats (hereafter referred to as capitals) were identified in the stakeholder workshops; these categories included environmental, social, economic, built, and governance. At the capital level, results from the coastal and watershed workshops were similar (Fig. 3).

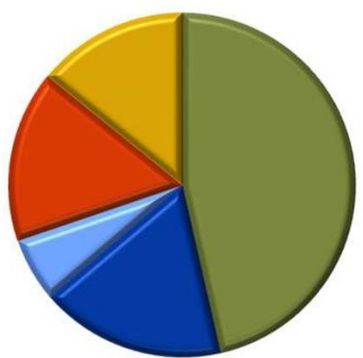

Watershed Workshop

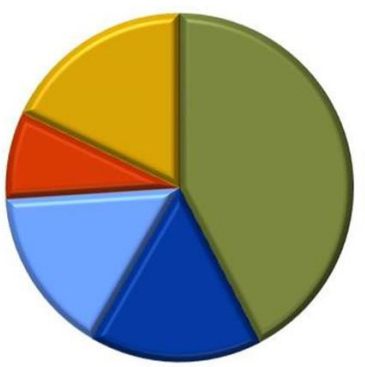

Coastal Workshop

Figure 3: Stakeholder workshop rankings of the major threats to a sustainable Mobile Bay system by capital category: governance (green), economic (dark blue), environmental (light blue), social (orange), and infrastructure (yellow).

The majority of threats to a sustainable Mobile Bay system identified by stakeholders were associated with the area of governance, which were nearly equal to the sum of all of the other threats combined. In the area of governance, two overarching subcategories of concern were identified:

- Lack of integration, a "silo mentality" or "stove-piping" of responsibilities at multiple levels of government - Participants expressed concerns associated 
with jurisdictional barriers and regulatory inconsistencies among governing agencies and groups

- Inability to understand interactions and trade-offs among environmental, social, economic, and built infrastructure concerns when evaluating a broad array of human activities

Major issues for the remaining four capitals were as follows:

- Economic - Human population growth and corresponding unfettered infrastructure development

- Environmental - Non-point source water quality and sediment issues

- Social - Public apathy or lack of understanding

- Infrastructure - Aging infrastructure, lack of resiliency to climate change impacts, and displacement by other market sector infrastructure

Participants expressed the view that a sustainable system was one that addresses all of the capitals without an excessive focus on any one in particular. These observations suggested a pressing need for a process model for effective governance that addresses multiple stakeholder needs by surmounting political and agency boundary issues. To this end, we developed a programmatic approach composed of robust strategies and a DSS framework for sustaining the MBFS that would:

- Restore and preserve environmental health

- Assure that relationships between human and environmental systems are recognized and respected

- Minimize negative effects of improving one system at the expense of another through an informed DSS process

This initial framework was designed to help managers prioritize restoration and preservation activities while

- Ensuring that social, environmental and economic outcomes are fully considered in management decisions

- Allowing managers to clearly communicate this information to stakeholders and the general public

Most importantly, it addressed restoration and sustainability through an outcomeoriented systems approach by providing an analytical construct to support communications and decisions while integrating existing science-based tools and their principal components wherever possible.

\section{Summary of DSS elements aligned with restoration strategy goals and priority actions}

This section identifies each of the four goals and recommended priority actions for the long-term ecosystem restoration strategy for the Gulf of Mexico [6], as well as provides an overview of the corresponding conceptual framework for a decision support system. A more detailed description of the content and basis for each decision support element is available in the final project report [12]. 


\subsection{Goal 1: restore and conserve habitat}

The strategy recommends the following priority actions to support the goal of restoring and preserving critical habitat:

1. Prioritize ecosystem restoration by ensuring that social, environmental, and economic outcomes are fully considered in all river management decision.

2. Improve sediment management using a "strategic use" approach.

3. Restore natural river processes of sediment and freshwater distribution.

4. Expand the network of conservation areas to ensure healthy landscapes.

5. Restore and conserve coastal and nearshore habitats.

Major elements of the decision support framework for Goal 1 include:

1. River system operations and system interactions models similar to those developed for the Missouri River System Master Manual Control Update $[13,14]$.

2. Dredge materials management information management system similar to those developed by the U.S. Corps of Engineers systems for San Francisco Bay [15].

3. Geospatial content management system of habitat types, target habitats and protected areas based on various resource management agencies records.

4. Indicators for species, habitats, environmental health and system functions $[16,17]$.

5. Geospatially explicit integrated land-use, economic, and habitat models similar to those used in the Pacific Northwest for sustainable forest management and complex multispecies habitat conservation plans [18].

6. Habitat restoration prioritization system based on principle components of the 2012 Louisiana Coast Master Plan [19] and Northwest Salmon restoration watershed prioritization systems [20].

\subsection{Goal 2: restore water quality}

The strategy recommends the following priority actions to support the goal of restoring water quality, including reduction/elimination of the large hypoxic area of the Gulf off shore of the Mississippi River delta:

1. Decrease nutrients in the Gulf through state nutrient reduction frameworks.

2. Focus restoration on priority watersheds to reduce hypoxic conditions.

3. Reduce pollutants and pathogens from stormwater flows and other sources.

4. Improve the quality and quantity of freshwater flow into priority estuaries.

Major elements of the decision support framework for Goal 2 include:

1. Land-owner based land use models of agriculture cost, yield, and best management practices (BMP) models based on principal components from NRCS CEAP Program [21] geospatially explicit forest estate and land use planning models used sustainable forest management [14].

2. Basin \& vector based the principle components from traditional EPA and U.S Corps of Engineers hydrological and water quality models.

3. Integrated modeling framework that links land-use operations, costs, benefits, and risks with BMP applications and water quality impacts in order 
to improve the valuation of BMPs on a geospatially relevant basis for both resource managers and landowners.

4. Outputs go into scenario-based modeling for TMDLs, market-based mechanisms, conservation program allocation, watershed management plans, and State nutrient management plans.

\subsection{Goal 3: replenish and protect living coastal and marine resources}

The strategy recommends the following priority actions to support the goal to replenish and protect living coastal and marine resources:

1. Restore depleted populations of living coastal and marine resources.

2. Conserve and protect offshore environments.

3. Restore and protect oyster and coral reefs, and other coastal environments.

4. Coordinate and expand existing Gulf monitoring efforts to track sentinel species and sites.

5. Minimize invasive species that impact on the Gulf.

Major elements of the decision support framework for Goal 3 includes:

1. Ecosystem-based management models for coastal and marine living resources [22-25].

2. Linkages to habitat prioritization, hydrological, and water quality models.

3. Geospatial planning land-use and habitat models that include functional linkages, scenario land uses, economics, and habitat models [14].

4. Indicators for species, habitats, environmental health and conditions, and system functions $[16,17]$.

\subsection{Goal 4: enhance community resilience}

The strategy recommends the following priority actions to support the goal to reduce human and environmental losses by enhancing community resilience:

1. Develop and implement comprehensive, scientifically based, and stakeholder-informed coastal improvement programs.

2. Provide analytical support tools to enhance community planning, risk assessment, and smart growth implementation.

3. Enhance environmental education and outreach.

Major elements of the decision support framework for Goal 4 include:

1. Storm surge, oceanographic, climate, and hydrologic models.

2. Built and natural infrastructure data systems.

3. Risk and impact models.

4. Socioeconomic models.

5. Adaptation strategies.

6. Integrated system to evaluate risk and adaptation alternatives and strategies.

7. Communication models.

The above system is conceptual based upon adaptation of the U.S. Department of Transportation (USDOT) Gulf Coast study of the impacts of climate change and variability on transportation systems and infrastructure [26] to address other human-made and natural infrastructure. 


\section{Conclusions}

The decision support system components described above can provide extensive benefits to stakeholders by reducing cost while improving the success of restoration. These benefits are derived holistically, consequently implementing this approach:

- Promotes a balanced recovery of the economy, culture, and environment.

- Provides a science-based support framework for informing stakeholder decisions and understanding social, economic, and ecosystem interactions.

- Addresses governance barriers.

- Increases stakeholder alignment and decision-making transparency by aligning objectives and actions of multiple organizations.

- Provides a holistic, systematic approach to management and restoration.

- Addresses ecological connectivity and critical geospatial relationships.

- Advances climate risk and adaptation tools to reduce human and economic losses from tropical storms and climate change.

- Improves the efficiency and outcomes of the allocation of billions of dollars of farm conservation grants to improve water quality.

- Allows scaling from pilot program to entire watershed and marine environment applications.

As stated previously, this investigation reports the findings of the framework conceptualization phase (Phase 1) for a proposed decision support system to support the long-term ecosystem restoration of the GoM under the Restore Act. As part of the assessment, two additional phases have been identified:

- $\quad$ Phase 2 (Collaborative System Development) consists of implementing the conceptual design of the DSS Framework for the MBFS, with considerations for the goals of the larger Gulf recovery strategy. Major steps in this process include initiating alignment and outreach, conducting a sub-model definition and development, and performing model integration.

- $\quad$ Phase 3 (Application and Adaptive Management) consists of implementing the conceptual design of the DSS Framework for the MBFS, with considerations for the goals of the larger Gulf recovery strategy. Major steps in this process include conducting model calibration and scenario development, conducting prioritization and information outreach, and performing the steps for technology transfer and adaptation.

The first step of Phase 2, alignment and outreach, is to assemble the investigation organizational structure to guide and direct the effort throughout the remainder of the investigation. The next steps were designed to encourage a collaborative approach throughout the execution of the next two phases with contributions from resource managers, stakeholders, and technical experts from across the Gulf in order to: (1) benefit from and build upon extensive knowledge of the system and varying perspectives, (2) ensure the framework is robust in order to address the varied conditions and stressors across the region, and 
(3) obtain stakeholder buy-in for a systematic approach for ecosystem restoration and thereby increasing the usefulness of the resulting decision support system.

\section{References}

[1] Waters, P. Oyster Gardening on Mobile Bay. In Auburn University Marine Extension and Research Center - Sea Grant Extension (Ed.), 08: 3, 2009.

[2] GOMPO. General Facts about the Gulf of Mexico. Stennis Space Center: Gulf of Mexico Program Office. 2011.

[3] NMFS. Fish Stocks in the Gulf of Mexico: Fact Sheet. In National Oceanic and Atmospheric Administration (Ed.): 1(3), 2010. U.S. Department of Commerce.

[4] Shelby, R. Senator Shelby announces funding for area commerce, justice, science projects. In U.S. Senate Press Release. Washington, D.C. June 26, 2007.

[5] Mabus, R. America's Gulf Coast: A Long Term Recovery Plan after the Deepwater Horizon Oil Spill. In EPA (Ed.): 130, 2010. Washington, D.C.

[6] GCERTF. Gulf of Mexico Regional Ecosystem Restoration Strategy. Environmental Protection Agency (Ed.): 1-128, 2010. Washington, D.C.: Gulf Coast Ecosystem Restoration Task Force.

[7] Wallace, R. K. Alabama Coastal Waters: Fact Sheet. In Alabama Cooperative Extension System (Ed.): 1-2, 1994. Mobile, AL: Auburn University Marine Extension and Research Center.

[8] EPA. Gulf of Mexico National Estuary Program Coastal Condition: Mobile Bay National Estuary Program. In EPA (Ed.), National Estuary Program Condition Report: 266-277, 2007. Washington, D.C.: U.S. EPA.

[9] ADCNR. Conserving Alabama's Wildlife: A Comprehensive Strategy. In Alabama Department of Conservation and Natural Resources (Ed.), Final ed.: 322. Montgomery: Alabama Department of Conservation and Natural Resources. 2005.

[10] USFWS. Mobile River Basin Aquatic Ecosystem Recovery Plan: 128. 2000.

[11] MBNEP. Working Together: Supporting Organizations and Program Documentation. In M. Mullins, H. Burch, M. Dardeau, and D. Sturm (Eds.), Comprehensive Conservation and Management Plan, Final ed., 3: 1-439, 2002. Mobile: Mobile Bay National Estuary Program.

[12] Hale, D.P., Hanson, D.A., Hachmeister, L., Britney, E., Hassler, E., Thompson, S. and Woolridge, R. Fisheries Infrastructure, Investigation, Assessment: Sustaining the Alabama Gulf Coast Fishery Resources. NOAA Award\# NA08NMF4520546 Final Report. January, 2012.

[13] U. S. Army Corps of Engineers Northwestern Division, Reservoir Control Center. Missouri River Mainstem Reservoir System - Master Water Control Manual, revised March 2006 http://www.nwd-mr.usace.army.mil /rcc/reports/mmanual/MasterManual.pdf

[14] Montagna, P. Harte Research Institute, Texas A\&M University, Corpus Christi. Blueprint for Managing Essential Freshwater Inflows into 
World's Bays and Estuaries. 2013 http://www.harteresearchinstitute.org /what-s-new

[15] U. S. Army Corps of Engineers San Francisco District Dredge Material Management Office http://www.spn.usace.army.mil/Missions/Dredging WorkPermits/DredgedMaterialManagementOffice(DMMO).aspx

[16] McKinney, L., Tunnell, W., Harwell, M., Gentile, J., Kelsey, H., and Dennison, B. Prospectus, Gulf of Mexico Report Card Initiative. May 2011 http://www.harteresearchinstitute.org/newsletter/spring2011/docs/ gom_report_card_initiative.pdf

[17] Jackson, L.E.E., Kürtzn, J.C., and Fisher, W.S. eds. Evaluation Guidelines for Ecological Indicators. EPA/620/R-99/005. U.S. Environmental Protection Agency, Office of Research and Development, Research Triangle Park, NC. 107 2000. http://www.epa.gov/emap/html/pubs/docs /resdocs/ecol_ind.pdf

[18] Hicks, L.L., and Stabins, H.C. A Case Study of Habitat Conservation Plans and the Protection of Snags and Coarse Woody Debris on Industrial Forest Lands. USDA Forest Service Gen. Tech. Rep. PSW-GTR-181. 2002.

[19] Louisiana Coastal Protection \& Restoration Authority. Louisiana's 2012 Coastal Master Plan. http://www.coastalmasterplan.louisiana.gov/

[20] Blair, G. R., L. C. Lestelle, and L. E. Mobrand. The Ecosystem Diagnosis and Treatment Model: A tool for assessing salmonid performance potential based on habitat conditions. Pacific Salmon Environment and Life History Models. Bethesda, MD: American Fisheries Society. Pages 289-309, 2009.

[21] USDA NRCS. Comprehensive Effects Assessment Project (CEAP). http:/www.nrcs.usda.gov/wps/portal/nrcs/detail/national/technical/nra/cea $\mathrm{p} /$ ?cid=nrcs143_014135

[22] NOAA, National Marine Fisheries Service. Ecosystem-based Fisheries Management: A Report to Congress by the Ecosystems Principles Advisory Panel. In NOAA, U.S. Department of Commerce (Ed.): 1-62. Silver Spring, MD: National Marine Fisheries Services. 1999.

[23] U.S. Fish and Wildlife Service (USFWS). Policy / Management Guidance, Part 052: Ecosystem Approach to Fish and Wildlife Conservation. Retrieved from http://www.fws.gov/policy/052fw1.html. 2002

[24] USFWS. (2011). Ecosystem Conservation. Midwest Region program page. http://www.fws.gov/midwest/EcosystemConservation/eco_outline 1.html.

[25] McLaughlin, R. Ecosystem-based Management in the Gulf of Mexico: Opportunities and Challenges. SandBar 7:3, October, 2008.

[26] USDOT. Impacts of Climate Change \& Variability on Transportation Systems \& Infrastructure: The Gulf Coast Study, 2011 http://www.fhwa.dot.gov/environmentclimate_change/adaptation/ongoing _and_current_research/gulf_coast_study/gcs.p_pdf 